\title{
EC Traceability System Design of Auto Parts Used Dual-Band RFID
}

\author{
Peng Peng ${ }^{1+}$ and Dongping Wei ${ }^{2}$ \\ ${ }^{1}$ School of Automotive and Transportation Engineering, Shenzhen Polytechnic,Shenzhen, China \\ ${ }^{2}$ Math and Physics Department, Shenzhen Polytechnic,Shenzhen, China
}

\begin{abstract}
Aiming at the rapid development of automobile after-sales service and auto parts deal,the paper creates dual-band RFID label to automatically identify auto parts for different purposes, combines with IoT technology, designs security and traceable algorithm that bounds dual-band codes and auto part information registration. Through the research on sales patterns and circulation patterns, the comprehensive e-commerce system of auto parts with $\mathrm{B} / \mathrm{S}$ structure is established includilng information support,logistics support,sales channels support based IOT, to achieve lifecycle traceability,anti-counterfeit and transaction management of all kinds of auto parts.It is applied to procurement, storage,sales, customer service,maintenance,recirculation of auto parts.It allows the government, auto parts dealers and consumers to inquire about the source information and the location of auto parts at any time, to realize the lifelong warranty, anti-counterfeit and tracking of auto parts.
\end{abstract}

Keywords: dual-band, lifecycle of auto parts, traceability, anti-counterfeit.

\section{Introduction}

With the rapid increase of the number of automobiles in China after 2012,sales industry of auto parts has also been high-speed developed. Because access threshold of distribution market in auto parts is low and auto parts are difficult to distinguish, fake and shoddy phenomenon is very prominent. Auto parts' quality directly affects the quality of the car and driving safety.Therefore, it is very important to strengthen the management of part sales industry to improve after-sale quality, protect consumers' rights and reduce hidden dangers in road traffic.But as the main body of auto after-sales service, $4 \mathrm{~S}$ shops do not completely have automatic collection ability and processing analysis ability on the field of auto parts sales and maintenance,let alone customer excavations and big datas.

The recirculation of second-hand auto parts is related to the normative development of the whole automobile industry. If auto parts are given "electronic identity cards” , consumers will be more reassured to repair their cars, and government quality supervision will also be more effective. The designed anticounterfeiting RFID code contains all the key information of auto parts, which can assign a unique number to each second-hand auto part. The source information and the location of auto parts are recorded in the database in detail,which can be queried at any time to achieve product quality assurance and traceability. While adding information to RFID labels, the information is transmitted to the center database and enterprise sub-databases through network. By comparing the RFID label content of the auto part with the records in databases, consumer or company can effectively identify the counterfeit product.

The purpose of using dual-band RFID in the quality traceability system is to facilitate lifelong tracing and security of auto parts.UHF(Ultra High Frequency) in dual-band RFID is suitable for manufacturers, maintenance enterprises. HF(High frequency) in dual-band RFID is suitable for other enterprises and dealers and ordinary consumers.

+ Corresponding author. Tel.: +86-755-26731091; fax: +86-755-26731033.

E-mail address:ppjsj@ szpt.edu.cn. 
The dual-band label in UHF area records the unique auto parts code with only a few numbers just like "ID card number",it is read-only for most users,only a few government users,high-grade users and administrators can modify.The dual-band label in HF area records all attributes of auto parts with High volume codes,it is widely writable under appropriate authority.With the hash function MD5,HF code is hashed into code A.All the attributes of auto parts are stored in the center traceability database,including the field $\mathrm{B}$, and field $\mathrm{B}$ is created by hashing all the fields of one auto parts record in database.Through querying center traceability database by UHF code, we can find out the corresponding field B at database, and then match and compare the codes A in HF area, If consistent, label traceability is valid and auto part is genuine, otherwise is counterfeit.It can be seen that dual frequency coding can play a good anti-counterfeiting role.

Actually,the system designes four anti-counterfeiting technologies,they are explained in another forthcoming paper.

When there is a problem with auto part, the information in the production, maintenance, transportation, storage and sale is stored in the dual-band RFID label. According to the content of the RFID label in quality traceability system, the whole process can be traced back,helping to confirm the link of problem and the scope of the problematic products, even to use RFID reader to quickly find unsold problem products in the warehouse.Consumers can also take advantage of quality traceability system, confirm whether the purchased product is a problem product and whether it is within the scope of recall. In case of vehicle quality dispute in aftermarket, the relevant government department can quickly and accurately lock the source of auto part through anti-counterfeiting label, which can better help consumer to safeguard legal rights.

\section{Current Research}

The study of the traceability system, which was initially used in field of food safety, initially established in 1997 by European Union in response to the problem of mad cow disease.European Union issued No. 178/2002 decree on July 2002. All foods sold in EU since 2004 are required to be traced back. In the United States, the traceability function for auto parts is generally used in the purchasing systems of the three major auto manufacturers including GM, Ford and Chrysler. However, foreign parts use identification system by barcode codes instead of using more superior RFID codes, and there is no anti-counterfeiting treatment in the coding system, so it is difficult to prevent illegal operation from copying and impersonating the code. Also the information system of auto parts in Sales, maintenance,secondary sales, and other fields during lifecycl of auto parts has not been applied effectively and synthetically.

With regard to the traceability and anti-counterfeit integration of the automobile parts industry in China, Hangzhou has already enacted legislation in 2008, and the "regulations of Hangzhou City on the Administration of vehicle maintenance" implemented the traceability management system for the quality assurance of auto parts. Hangzhou's auto maintenance enterprises and parts market are already implementing "electronic identity cards" for auto parts. However, the system is not comprehensive enough to trace auto parts during lifecycle.

In 2018, the Fujian auto maintenance association of China plans to set up a traceability platform to divide all motor vehicle parts in Fujian Province into two categories according to the place where they are manufactured: the manufacturers of auto parts outside the province and the manufacturers of auto parts in the province.It possibly provides all Fujian Province auto parts traceability, but has not yet officially realized and applied.

Up to now, there is no monitoring and tracing system for the whole life cycle of auto parts, and the automobile industries and automobile enterprises involved in auto parts circulation cycle cannot be effectively integrated..This designed system can fill this gap.We design an anti-counterfeiting traceability algorithm which bounds dual-band encoding and auto part information registration.Based on the research of auto parts sales and logistics mode,we set up integrated e-commerce system of auto parts by dual-band RFID. It provides information support,logistics support and sales channel support,and achieves lifecycle traceability,anti-counterfeit and transaction management of all kinds of auto parts.

\section{System Framework}


System DB is Microsoft SQL Server2010 .UML is used to model, considering the need of system upgrade and security,the design of five-layer architecture(Fig.1) and RSA asymmetric encryption for important datas is adopted.

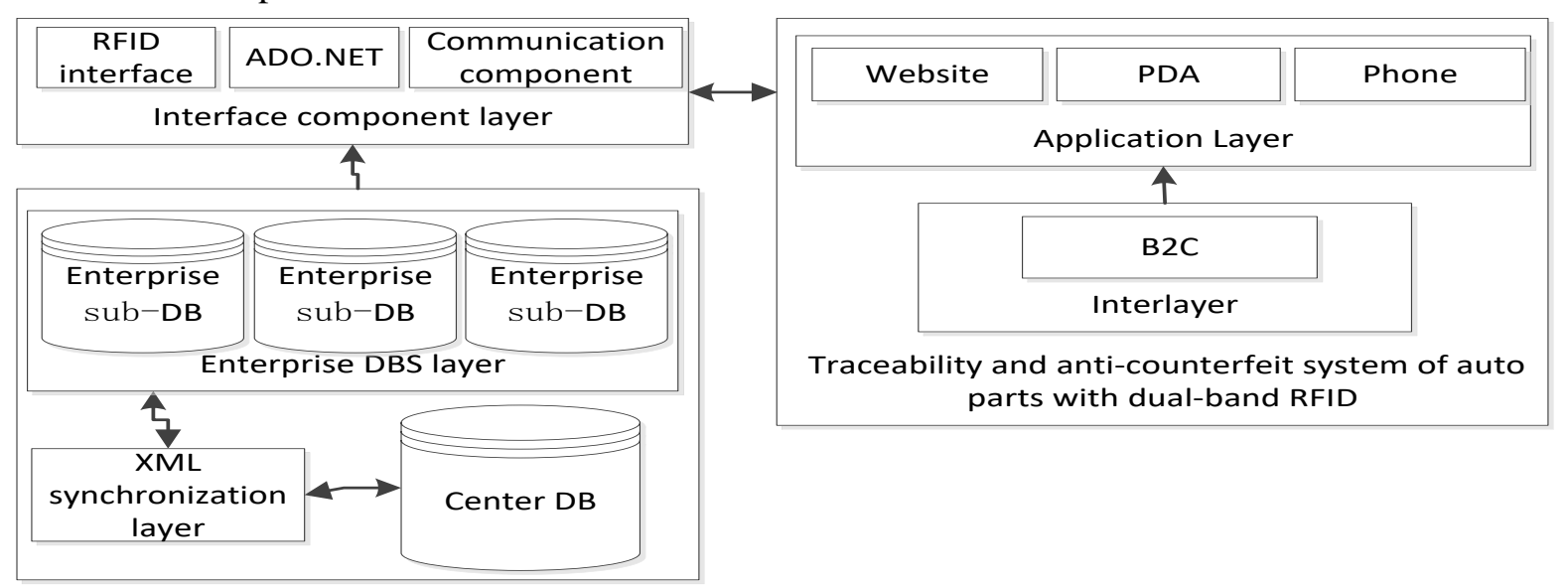

Fig. 1: System technical structure

The B2C traceability system uses ASP.NET technology as the server-side script to realize the web page ,and interacts with the database and other applications. The individual user can visit the B2C website on the server through the browser,inquire about the authenticity and traceability status of the auto parts.Use VB.NET to design a $\mathrm{B} / \mathrm{S}$ program that can be easily used.

There are two kinds of databases in the whole tracking and anti-counterfeiting system:the main traceability center database and the enterprise sub-databases. In order to ensure that there is no "dirty" data in the central traceability database, it is necessary to update the enterprise database to the central traceability database periodically.But the structure of the two databases may be different,so there exists the problem of data synchronization between heterogeneous databases. The synchronization and exchange technology of XML data is adopted and realized with ADO.NET.

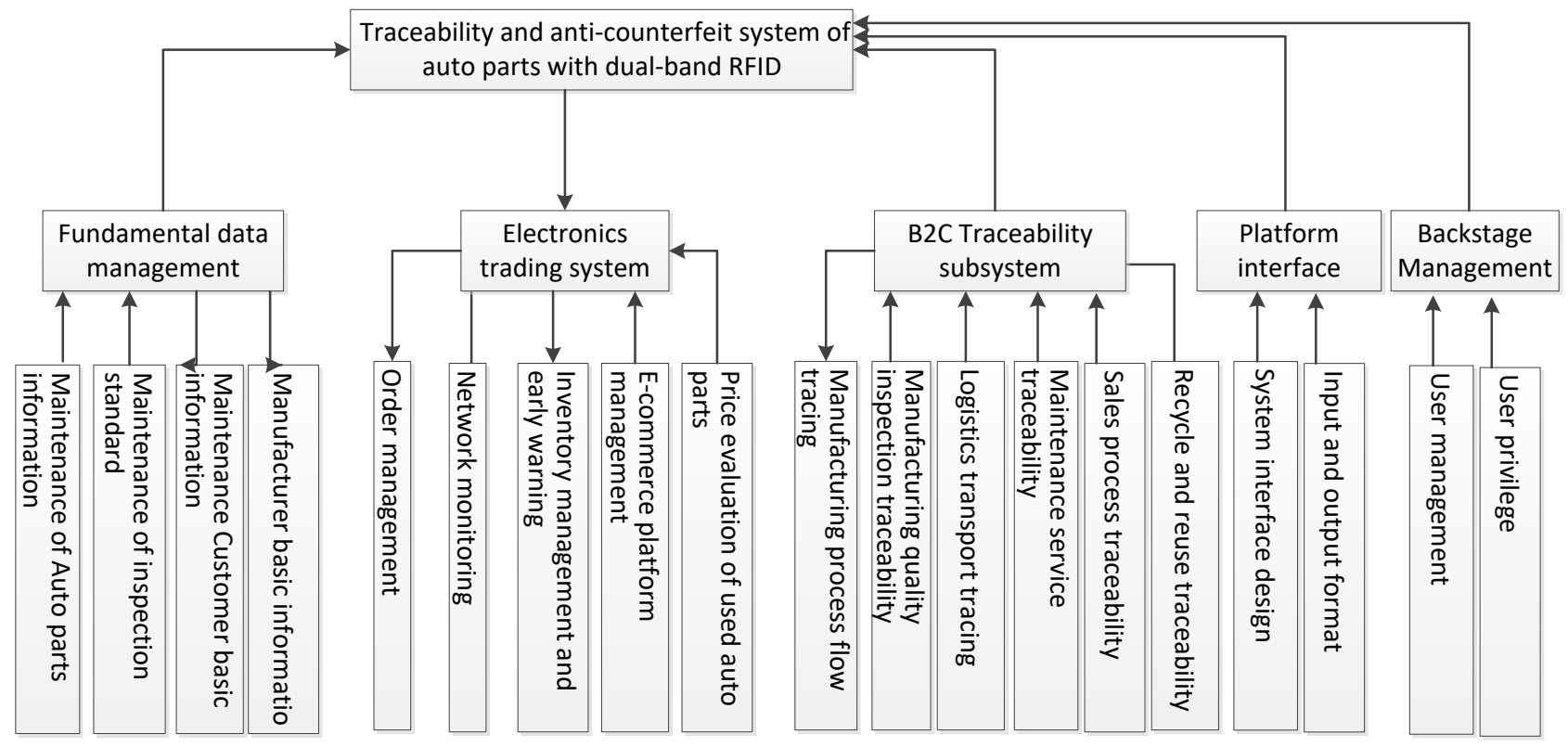

Fig. 2: System main function

Without regard to anti-counterfeiting function(it will be expounded in the other paper),the system includes six parts,the main function is shown in Fig. 2:

- Fundamental data management:the data of dual-band label management.It Includes auto parts basic information, maintenance of inspection standard,customer information, manufacturer information. 
- Electronics trading system:realizing the electronic commerce environment of auto parts' lifecycle,including order management, network monitoring, inventory management and early warning, electronic commerce platform management,price evaluation of reused auto parts.

- Traceability subsystem:tracing management in the whole lifecycle circulation of auto parts,including quality inspection tracing in production;logistics and transportation tracing in circulation;sales process tracing and maintenance service tracing in sales and after-sale;second-hand parts' recovery and reuse tracing in recirculation.

- Platform interface: the presentation layer of the system.It mainly invokes the function of the service interface layer, including the system interface design, the input and output format of each business process, and the generation of the realtime view according to the system.

- Database interface: the data component layer of the system.It realizes the data communication with the database.It uses ADO.NET to connect to the database, and uses stored procedure,function and trigger to each table object of the database to realizes the basic operation.

- Backstage Management: including user management, user privilege, upgrade and so on.

\section{Effects and Conclusions}

Traceability and anti-counterfeit system of auto parts with dual-band RFID can automatically identify auto parts for multipurpose, and allow the government, auto parts dealers and consumers to inquire about the source information and the location of any auto part at any time, and ultimately realize the life-long warranty, traceability and anti-counterfeit of auto parts.It contributes the safety and efficiency of lifecycle circulation for auto parts,promotes the healthy development of the whole automobile industry.

The designed traceability and anti-counterfeit system of auto parts with dual-band RFID is very effective to the automobile industries, enterprises and users. It mainly provides the electronic identity cards of auto parts with dual-band RFID to the automobile manufacturing enterprises,auto parts manufacturing enterprises and thousands of automobile sales and maintenance enterprises to improve operational efficiency.For auto parts and second-hand parts users, the system greatly improves the transparency of auto parts in production,logistics and market circulation, effectively ensures the quality of maintenance parts and recycling parts, and safeguards lawful rights and interests of consumers.

\section{Acknowledgments}

This work is supported by the funding from the excellent young teachers ( Peng Peng ) of guangdong university cultivation programme under grant YQ2015213.

This work was financially supported by Guangdong soft Science research project(2015A07070404) and the Project of philosophy and Social Sciences in Guangzhou(2017GZYB39).

\section{References}

[1] Peng Peng. Intelligent EC System on Recycling of Auto Parts. Tractor \& Farm Transporter.2012, 4: 68-71.

[2] Peng Peng. The Tracing System Of Auto Parts Based On Dual-Band RFID. Chinese Agricultural Mechanization.. 2012, 3: 153-157.

[3] Peng Peng,Qiang Zhang.Exploration of Recycling Auto Parts Monitoring System. Guangdong Science And Technology.2008, 5: 51.

[4] Changyong Liang,Wei Zhou,Meiju Cai,Junling Zhang.Research on Vehicle Quality Tracking System Under the Dual Frequency Label Management Mode.Computer Technology And Development.2010, 5: 171-174.

[5] Jianling Zheng. Each spare part is equipped with a unique "id card" [N]. China quality daily, 2018-01-09(006).

[6] Wei Zhang. Design and implementation of taiyuan automobile parts quality traceability system [D]. Dalian university of technology, 2016.

[7] Jin Wu. Research on the traceability system of automobile parts in fujian province based on RFID technology [J]. Computer and telecommunications, 2016(12):29-31. 